\title{
Deteriorating human microbiome - An emerging global health challenge
}

\section{Rahul Bansal}

Professor \& Head, Department of Community Medicine, Subharti Medical College Meerut, Swami Vivekananda Subharti University, Meerut, Uttar Pradesh 250005

\section{Corresponding Author}

Dr Rahul Bansal, Professor \& Head, Department of Community Medicine, Subharti Medical College Meerut, Swami Vivekananda Subharti University, Meerut, Uttar Pradesh 250005

E Mail ID: rbansal13579@gmail.com

\section{Citation}

Bansal R. Deteriorating human microbiome - An emerging global health challenge. Indian J Comm Health. 2021;33(3):417-418. https://doi.org/10.47203/IJCH.2021.v33i03.001

Source of Funding: Nil Conflict of Interest: None declared

\section{Article Cycle}

Received: 15/09/2021; Revision: 22/09/2021; Accepted: 26/09/2021; Published: 30/09/2021

This work is licensed under a Creative Commons Attribution 4.0 International License.

The study of human microbiome and its relationship with health and disease is one of the most exciting areas of research in health all over the world, especially after the failure of human genome project to deliver its expectedresults.

Our body is composed of 30 trillion human cells. But it is hostto close to 100 trillion bacterial and fungal cells. $70-90 \%$ of all cells in our body are non-human. They reside on every inchof our skin, in our nose, mouth, ears, in our oesophagus, stomach and most abundantly in our gut. They are not a random phenomenon but have co-evolved with us humans over millions of years. Collectively these bacteria weighabout 3 pounds. The more we read about research on microbiome or microbiota, the name given to all these friendly symbiotic partners, the more we get interested in their role in health and disease.

According to Martin J. Blaser, director of the Human Microbiome Program, who has also served as the president of Infectious Disease Society of America, in his best seller 'Missing Microbes' (1), "It is our microbiome that keeps us healthy and parts of it are disappearing. The reason for this disaster is all around us overuse of antibiotics in humans and animals, caesarean sections and widespread use of sanitizers and antiseptics, to name just a few."

From a well written article - 'Role of Gut Microbiota in Gut Nutrition and Health' (2) by Ana M Valdes and colleagues following are the key messages about the microbiome:-

- Gut microbiota influences many areas of human health, from innate immunity to appetite and energy metabolism.

- Targeting the gut microbiome with prebiotic or dietary fibre benefits human health and could potentially reduce obesity.

- Drugs, food ingredients, antibiotics and pesticides couldall have adverse effects on the gut microbiota.

- Microbiota should be considered a key aspect in nutrition, the medical community should adapt theireducation and public health messages accordingly.

- Fibre consumption is associated with beneficial effects in several contexts.

The above message looks very simple but there are a lot of conflicting issues when we think of recovering the lost diversity of human microbiome, for instance antibiotics definitely save lives but in their recently published book 'Let Them Eat Dirt' (3) B. Brett Finlay and Marie - Claire Arrieta have compared using broad spectrum antibiotics with carpetbombing the microbiota. The excessive and often unscientific use of antibiotics in paediatric and other age groups has been highlighted in many books- 'Missing Microbes'; 'Let Them Eat Dirt'; Gut- The inside story of our body's most underrated organ ' and different articles $(1,3,4,5,6)$.

So, the million-dollar question is when to use and when not to use antibiotics? Moreover, another big public health disaster related to this issue is the slowly growing worldwide phenomenon of multidrug resistant bacteria.

Even far bigger an issue is the use of antibiotics in small dosesto fatten the farm animals. Martin J. Blaser (1) has clearly highlighted this practice by the meat industry. Theseantibiotics enter our food chain and are grossly affecting ourmicrobiome's diversity leading to both short and long term health consequences.

The third controversial issue regarding human microbiome is the use and overuse of Caesarean section for delivery of human child. Over the years a growing trend of Caesarean sections has been noted worldwide. According to an article in Science Daily (7) Caesarean section use has almost doubled globally since 2008. When a child is not delivered naturally he/ she loses the golden opportunity to kick start his microbiome through exposure to secretions of mother's birth canal and faecal matter. 
The fourth contentious issue in post COVID era is the use and overuse of sanitizers and other antimicrobial products. Already there are concerns that the overuse of antimicrobial agents through hygiene products may lead to changes in microbiome pattern among human beings globally. (8)

We are already aware about the debate going on over the 'hygiene hypothesis ' which in simple terms says too much of cleanliness in early childhood, which is quite common thesedays in urban India and the western world may compromisethe proper diversification of microbiome leading to dire long term consequences such as diabetes type 1 (9), obesity, Bronchial Asthma and other auto immune diseases. $(3,10)$ Interestingly there are well written review articles and booksshowing a two way pathway between the gut microbiomeand mental well being. As given in a review article inGastroenterology (11) there appears to be a closerelationship between intestinal microbiota and the central nervous system in normal gastrointestinal function anddiseases. Diseases like depression and anxiety are beinglinked with health of microbiome.

In a mini review article the 'Human Microbiome and Cancer the authors Seesandra V. Rajagopala et. al (12). have highlighted the role of human microbiome in cancer as the resident microbiota plays an essential role in activating and modulating the host immune response. Immunologicaldysregulation is likely to provide mechanistic explanation as to how our microbiome affects cancer development andcancer therapies.

Also, there are studies showing the relationship between gut microbiome and coronary artery disease and heart failure. (13)

Martin J. Blaser compares this man-made destruction of our 'micro ecology' (partial destruction of microbiome) with the transformation of the 'macro ecology' of our planet through global warming and other environmental catastrophes. He even goes on to say that the ill effects of the former may be equally disastrous and on a shorter time frame.

What are the solutions? They are simple but need collective and focused action by the mankind with the same urgency asis being shown about climate change.

\section{To name a few obvious solutions}

- $\quad$ Strictly restrict the use of antibiotics and accompany every broad spectrum antibiotic course with probiotics among human beings - an issue which looks simple but needs a lot of hard work in training doctors, the public and owners of medical stores.

- Ban the use of low dose antibiotics among farm grown animals - which has already been done in many European countries.

- Caesarean section should be done only as a life saving measure for the mother and child and no other reason. This againneeds training of doctors and sensitization of would be mothers.

- $\quad$ The children from early age should be allowed to mix freely with their family and friends and breastfeeding should be the only choice in early childhood as there is enough evidence to link healthy microbiome in breastfed babies compared to the bottle fed babies. (14)
- Over sanitizing the child's world should be avoided though cleanliness is definitely the need for the growing child.

- $\quad$ The foods which harm the microbiome should be avoided such as tobacco, alcohol, fast foods, artificial sweeteners, and foods containing insecticides and pesticides.

- The foods which help the healthy microbiome to flourish (prebiotics) should be encouraged from early childhood such as - fresh fruits and vegetables, whole grains, other natural foods with high fibre content and fermented foods like curd, buttermilk, etc.

We know enough about the role of microbiome and human health and also its strong link with our health and well being. It is up to us to act now or face the consequences at individual and collective levels.(15)

\section{Acknowledgement}

The author acknowledges the help received from Dr. Shradha Kaushik, MBBS Intern posted in department of Community Medicine, SMC Meerut.

\section{References}

1. Blaser MJ. Missing microbes: how the overuse of antibiotics is fuelling our modern plagues. New York: Picador; 2015.

2. Valdes AM, Walter J, Segal E, Spector TD. Role of the gut microbiota in nutrition and health [Internet]. The BMJ. British Medical Journal Publishing Group; 2018. Available from: https://www.bmj.com/content/361/bmj.k2179 (Last accessed on 25.09.2021)

3. Finlay BB, Arrieta M-C. Let them eat dirt: saving your child from an oversanitized world. London: Windmill Books; 2017

4. Van Houten $C B$, Cohen A, et al. Antibiotic misuse in respiratory tract infections in children and adults-a prospective, multicentre study (TAILORED Treatment). Eur J Clin Microbiol Infect Dis. 2019 Mar;38(3):505-514.

5. Francino MP. Antibiotics and the Human Gut Microbiome: Dysbioses and Accumulation of Resistances. Front Microbiol. 2016;12(6):1543.

6. ENDERS GIULIA. Gut: the inside story of our bodys most underrated organ; trans. by david shaw.

7. Caesarean section use has almost doubled globally since 2000 [Internet]. ScienceDaily. ScienceDaily; 2018.Available from: https://www.sciencedaily.com/releases/2018/10/ 181011190654.htm (Last accessed on 25.09.2021)

8. Ejtahed HS, Hasani-Ranjbar S, Siadat SD, Larijani B. The most important challenges ahead of microbiome pattern in the post era of the COVID- 19 pandemic. J Diabetes Metab Disord. 2020;19(2):1-3

9. Candon $S$, Perez-Arroyo A, Marquet $C$, Valette F, Foray A-P, Pelletier B, et al. Antibiotics in Early Life Alter the Gut Microbiome and Increase Disease Incidence in a Spontaneous Mouse Model of Autoimmune InsulinDependent Diabetes. Plos One. 2015;10(5).

10. Proal AD, Albert PJ, Marshall TG. The human microbiome and autoimmunity. Current Opinion in Rheumatology. 2013;25(2):234-40.

11. Collins SM, Bercik P. The relationship between intestinal microbiota and the central nervous system in normal gastrointestinal function and disease. Gastroenterology. 2009;136(6):2003-14

12. Rajagopala SV, Vashee S, Oldfield LM, Suzuki Y, Venter JC, Telenti A, Nelson KE. The Human Microbiome and Cancer. Cancer Prev Res (Phila). 2017;10(4):226-234

13. Trøseid $M$, Andersen $G \varnothing$, Broch $K$, Hov JR. The gut microbiome in coronary artery disease and heart failure: Current knowledge and future directions. EBioMedicine. 2020;52:102649.

14. van den Elsen LWJ, Garssen J, Burcelin R and Verhasselt V. Shaping the Gut Microbiota by Breastfeeding: The Gateway to Allergy Prevention? Front. Pediatr. 2019;7:47. doi: 10.3389/fped.2019.00047

15. School of Medicine The Moore Institute [Internet]. OHSU. Available from: https://www.ohsu.edu/school-of-medicine/mooreinstitute/breastfeeding-and-microbiome (Last accessed on 25.09.2021) 